\author{
Michael Mitchell, Arizona State University
}

Comparative politics need not beat a hasty retreat in the face of the paradigmatic disarray occasioned by the unpredicted collapse of the former Soviet Union. On the contrary, students of comparative politics are in a position actually to witness the process wherein societies struggle for new solutions to such classic questions as: how nations peacefully consolidate a central authority; how nations formulate and reformulate the principles that give legitimacy to a country's central authority; and, under what circumstances nations may wish to redefine the relationship between citizen and state. Organizing courses around some of these issues can make students aware of both the immediacy of these issues as well as of the intellectual continuity in the study of comparative politics. The following is a brief sketch of some other issues around which an introductory comparative politics might be organized, specifically regarding the development of democracy in the Third World.

\section{Democracy in the Third World.} One of the distinguishing features of what Samuel Huntington calls "the third wave of democracy" is the number of countries involved. The prior democratic cycles that occurred in the late eighteenth and nineteenth centuries comprised a handful of countries located in a specific geographical region that had inherited a legacy of similarities in culture, traditions, and standards of material life. The twentieth-century cycle of democratization on the other hand encompasses nations at varying levels of socioeconomic development, with varying cultures and historical circumstances, spread throughout every continent on the globe.

Moreover, the democratization of the late twentieth century, characterized by its location principally in the Third World, is removed from the dual revolutions of democracy and industrialization which were so closely intertwined in the nineteenth-century wave of European democratization. In some instances rapid industrialization in the twentieth century has proven to be an obstacle to democratization. In a real sense Third World democracies find themselves reinventing the democratic project in circumstances significantly unlike those of Europe. The Third World constitutes the area where the most crucial contemporary tests of democratic politics are taking place, so students of comparative politics should naturally focus their attention on this area.

Studying democracy in the Third World poses a distinct set of intellectual problems. The most fundamental, perhaps, is establishing some frame of reference for analyzing a familiar Western idea in circumstances that lie outside the historical experience of the West. Rescuing discussions of comparative politics from the dangers of ethnocentrism is no easy task, however.

One serious intellectual fault that Western scholars continue to fall prey to is the posture of triumphalism. At first glance, triumphalism paints an intellectually ambitious vision of progress that appeals to an optimistic faith in the possibilities for improving the human condition. On reflection, however, triumphalism obscures rather than enlightens. It reduces the study of politics to a simple matter of describing how others copy their experiences from a single master plan of history. Moreover, it narrows the scope of discourse to the point of denying the possibility of multiple inspirations for the values that underlie all human communities.

Color and democracy. If the task of explaining the democratic project in the Third World requires more than what a triumphalist interpretation has to offer, how does one begin to explore the emergence of democracy in the Third World?
Reference to the notion of dialectic, the creation of synthesis from the clash of opposites, would be a useful starting point. W.E.B.

DuBois (1945) made use of this interpretive vehicle in his brief book advocating the liberation of European colonies at the end of World War II.

Taking the European powers head on, DuBois criticized their efforts to construct a post-war order based on the colonial status quo ante. DuBois was particularly critical of the belief that those living under colonialism lacked cultural preparedness for independence. His devastating analysis of the social and economic conditions inflicted on the people of Africa and Asia left no doubt about where the blame lay for any presumed lack of preparation to assume leadership in the independent and democratic states to be carved out of a colonial world.

Dubois's analysis led him to conclude that the remedy for social, economic, and cultural dislocations caused by European imperialism lay in the direction of self-government and genuine democracy. He counterpoised several of colonialism's destructive processes with dialectical solutions. Imperialism's economic monopolies would be challenged by the creation of indigenous ownership; colonialism's cultural distortions would be overcome through education; and arbitrary rule would be replaced through government based on universal suffrage. An essay such as DuBois's could be used to great advantage in any normative discussion of the propriety of democracy in the Third World.

Comparing democracies from $\mathrm{Fed}$ eralist \#9. Alexander Hamilton made the following assertion: "To [the] catalogue of circumstances that tend to the amelioration of popular systems of civil government I shall venture ... to add one more ... I mean the ENLARGE- 
MENT of the ORBIT [sic] with which such systems are to revolve, either in respect to the dimensions of a single state, or to the consolidation of smaller states into one great Confederacy [sic]"' (Hamilton, et al. 1961, p. 73). In Federalist \#9, Hamilton contended that the territorial proportions of a republic would serve as one of the major safeguards of popular government. Small republics, Hamilton argued, were the most vulnerable to overthrow and capture by factions. Based on this observation, Hamilton formulated a general proposition of cause and effect meant to be applicable to an entire universe of instances: the larger the republic, the greater the safeguard against tyranny and factions.

Notwithstanding various controversies about its historical consequences, as a general proposition Federalist \#9 can serve as a vehicle for exploring several dimensions of comparative politics. Countries can be classified, for example, according to the descriptive components of the proposition and labeled as continental democracies. Outside of the advanced industrial nations and Eastern Europe, Brazil, India, and Nigeria fit this description. Do these nations in fact share common characteristics and do they face common problems that would merit their classification as a distinct group of nations?

Brazil, India, and Nigeria display sociological patterns related to the evolution of democratic states. In each case, oligarchies have assumed an importance under formal democracies. In fact, much of the histories of these nations can be understood as the struggle of rival oligarchies for control of the institutions of the state. Indian politics, for example, experienced a profound transformation in the first decades of independence as the independence political elite effectively sapped the power of the maharajahs. Similarly, in Brazil, advances in democratization came about by the displacement of one set of rural elites by an alliance of urban professionals with another set of rural oligarchs. The question that this pattern poses for discus- sion is whether, as Claudio Veliz (1980) has argued, the long road to democracy must necessarily begin in oligarchical politics.

Brazil, India, and Nigeria share another common pattern. In the course of their independent histories each has experienced the breakdown of democratic government. On varying occasions each has had to reconstruct a democratic state after a prolonged period of authoritarian rule. Their responses to what Juan Linz terms "reequilibration" (1978) have differed, however. The Indian case represents the importance of party dynamics. Nigeria illustrates military monopoly over the politics of democratic transition. Brazil's transition politics has involved a wide array of military and civilian elites who alternated between bargaining and confrontation to achieve the consensual extrication of the military from politics. These three alternatives suggest the rich variety of solutions to the dilemmas confronting continental democracies.

The normative stakes in studying Third World continental democracies are high. Countries like Brazil, India, and Nigeria exercise a "demonstration effect" in which developments in these nations can have a profound impact on others. If democracy is to find fertile ground in the Third World, much of its flowering will come from nations to whom others look for inspiration.

Political identity. Throughout the Third World the problem of defining citizenship and other fundamental political identities is crucial. The issue of political identity takes on added urgency because a complex web of ethnic, language, and religious cleavages characterizes many Third World nations. Nevertheless, the cultural attributes of language, religion, and ethnicity more often than not have been treated by Western scholars as the traits of an archaic order which inevitably have to give way to more modern cleavages such as class.

These cultural characteristics have shown a remarkable resiliency, however. Contemporary anthropology has gradually come to recognize that primordial affinities, rather than disappearing under the pressures of modernization, have reinvented themselves to preserve essential values and beliefs in a world transformed rapidly by industrialization, urbanization, and the penetration of a world economy into the remotest of human settlements (Clifford 1988).

Third World nations, and Western nations as well, must deal in some concrete way with these reinvented ancient identities in ways that account for both the cultural richness they offer as well as the political conflicts they engender. At the very least, they compel us to take another look at institutional arrangements that attempt to meet these kinds of challenges.

Conclusion. It is only recently that democracy has emerged in the Third World as a model of politics with any widespread attraction or inspirational force. Generally speaking, regimes like authoritarianism, military rule, and one-party states, or the unsettling alternation between democracy and authoritarianism, have been the rule rather than the exception. Third World politics is not so far removed historically from this past for some to question whether Third World nations have acquired whatever prerequisites are needed to sustain stable democratic regimes.

Certainly a mining of the literature on the prerequisites of democracy may contribute to the debate. Levels of social and economic development, size and strength of a national bourgeoisie, and the degree of a nation's penetration by the world capitalist system continue to provide important insights.

Another side to democratic development should not go unnoticed. If Europe can in any way serve as a model of development for the Third World, it should be as a cautionary tale. Even in Europe, democracy suffered rollbacks of sufficient proportions to convince thinkers such as Marx that it was a failed vision of society. In whatever circumstances, democracies are fragile arrangements that do not always stand up to the test of polit- 
ical crisis and strain. The European experience of the inter-war years certainly confirms this.

Nevertheless, democracies prevail by conscious design and commitment (Linz 1978). It depends on the informed choices made by those committed to democracy in a complex world of ambiguity. One goal of teaching comparative politics ought to be to develop an appreciation of these complexities and of the almost limitless solutions to age-old questions about how to build human communities.

\section{References}

Clifford, James. 1988. The Predicament of Culture. Cambridge: Harvard University Press.

DuBois, W.E.B. 1945. Color and Democracy. New York: Harcourt and Brace.

Hamilton, Alexander, et al. 1961. The Federalist Papers. New York: New American Library.

Linz, Juan. 1978. The Breakdown of Democratic Regimes: Crisis, Breakdown, Reequilibrium. Baltimore: Johns Hopkins University Press.

Veliz, Claudio. 1980. The Centralist Tradition of Latin America. Princeton: Princeton University Press.

\begin{abstract}
About the Author
Michael Mitchell is an associate professor at Arizona State University. He teaches the introductory comparative politics course there. His research field is Latin American politics. He is the recipient of the Dean's Quality Teaching Award of the College of Liberal Arts at A.S.U. In addition he serves currently as chair of the Test Development Committee of the College Board's Advanced Placement Government and Politics program.
\end{abstract}

\title{
Narrowing the Focus of Introductory Comparative Politics Courses
}

\author{
Joseph L. Klesner, Kenyon College
}

What is the purpose of the introductory course in comparative politics? I grow more and more concerned that those of us who teach introductory comparative politics courses are expected to accomplish too many goals in a single introductory course. First and foremost, I would like an introductory comparative politics course to excite students about the empirical study of political change, political processes, major political struggles, and the institutionalization of significant political ideas wherever they might occur and whenever they might have occurred. I would like to see students leave their first course in comparative politics excited enough about the empirical study of politics in places other than their own country and convinced enough of the importance of knowing about the political experiences of other societies so that they are ready to immediately sign up for another comparative politics or area studies course.

Unfortunately, most standard comparative politics courses-including the one that I taught for six years-are not accomplishing that goal. The macro-level, whole-systems approach that so many use is problematic because it is difficult to gain more than superficial knowledge of a country when four or five countries are explored in a semester. Simple coverage of institutions of major foreign powers is usually considered dull by students. Emphasizing the comparative method, a worthy goal, by introducing and comparing interesting or important political processes, institutions, and theoretical constructs of comparative politics in critical case contexts risks not teaching the students enough about the politics of major foreign governments to ensure that they can be informed citizens.

If we survey, not the textbooks for comparative politics, but the catalogue of a publisher in comparative politics, I think we will find a principle of organization for an introductory comparative politics course that also takes introducing the comparative method seriously. When we look at those publishers' catalogues, what kinds of books catch our eye? Probably case studies that are also intended as theorybuilding enterprises. Certainly this is what we've mostly done as our own scholarly work from the dissertation onward. These case studies explore a narrow topic, conceptual or institutional, attempting to build or disprove theoretical constructs about that topic. In so doing, they must provide a sufficient context of a country setting, with a little about history, economic and social structure, and culture, so that the reader can see how the political institution or process operates within a political system.

The kind of introductory comparative politics course that I'm advocating would be restricted to one or a couple of linked topical issuesrevolution, the nature of democratic regimes, economic and social policy, nationalism and/or statebuilding, electoral politics and party system dynamics, and others that have motivated our scholarly interests. These are usually topical issues at the center of the discipline. Often a major work of a major social scientist is available as a book that can provide an anchor for students in the course, a book to which they can return to review the theoretical issues at stake and perhaps see how a major scholar systematically compares two or three or maybe four countries as he or she applies the theory to relevant cases.

Then the monographic studies of three or four critical or important cases can be used to introduce the empirical material from those cases. Most of these critical cases are about countries we consider as major foreign governments - the number of monographic studies of Germany, the former Soviet Union, Japan, France, China, and so forth 